\title{
A PREVALÊNCIA DO TABAGISMO ENTRE ESTUDANTES DE GRADUAÇÃO DA SCOLA DE ENFERMAGEM DA UNIVERSIDADE DE SAO PAULO
}

\section{THE SMOKING PREVALENCE AMONG UNDERGRADUATE STUDENTS OF THE UNIVERSITY OF SAO PAULO, SCHOOL OF NURSING}

OGUISSO, T.; SEKI, LK. A prevalência do tabagismo entre estudantes de graduação da Escola de Enfermagem da Universidade de São Paulo. Rev Esc EM USP, v.35, n. 1, p. 19-27, mar. 2001.

\section{RESUMO}

Estudo feito entre estudantes da EEUSP para saber se eles eram fumantes habituais ou ocasionais, e se esse hábito havia sido adquirido antes ou depois do ingresso na Escola. Do total de 314 estudantes matriculados em 1998, 80,9\% responderam ao questionário, dos quais 49,2\% já haviam experimentado fumar, e dentre esses, 38 continuavam a fumar na data do estudo. Entre os fumantes encontrados, 16 haviam começado a fumar dos 16 aos 20 anos, 12 com menos de 15 e três com 21 anos ou mais. Ao final, propõe-se que a EEUSP coloque maior quantidade de placas de "proibido fumar" no ambiente da escola; realize seminários periódicos sobre tabagismo para incentivar docentes e alunos a deixarem de fumar; participe ativamente do Dia Mundial sem Tabaco ou inclua essa atividade no programa do CCEx. Enfim, que se divulgue os dados e estatisticas da OMS sobre as conseqüências do tabagismo.

PALAVRAS-CHAVE: Tabagismo. Promoção da saúde. Tabaco. Estudantes de enfermagem.

\begin{abstract}
Survey among undergraduate students to find out whether they were daily or occasional smokers, and whether this habit was acquired before or after their entrance into the School. From the total of 314 students registered in 1998,,80,9\% filled out the questionnaire, among those 49,2\% have already experienced to smoke, and 15,0\% have continued smoking at the date of the study. Among smokers, 16 have started to smoke between the age of 16 and 20, 12 students started before, and three at age 21 or older. At the end, it is proposed that the School spread out "no smoking" signs within its environment; periodically organise workshops and seminars to encourage lecturers and students on smoking cessation; to actively participate in the World no Tobacco Day or include such activity in the work of a specific committee. At last, to disseminate WHO data and statistics on smoking consequences.
\end{abstract}

KEYWORDS: Smoking. Health promotion. Tobacco. Students nursing.

\section{INTRODUÇÃO}

$\mathrm{Na}$ vida moderna, o fumo está se tornando um hábito comum entre pessoas de ambos os sexos e de todas as idades. A World Health Organization (24) ou, Organização Mundial da Saúde (OMS) alerta que, em todo o mundo há mais de um bilhão de fumantes; e que em paises industrializados $41 \%$ dos homens e $21 \%$ das mulheres fumam cigarros regularmente e nos países em desenvolvimento essa relação é de $50 \%$ de homens para $8 \%$ de mulheres, mas que o número de mulheres fumantes está aumentando em muitos países. A cada ano 6 bilhões de cigarros são consumidos. Enquanto nos países industrializados houve uma queda no consumo anual de cigarros, de 2800 unidades por adulto no inicio da década de 80 para 2400 no inicio da década de 90 , nos países menos industrializados, o que constitui três quartos da população mundial, o consumo por adulto aumentou de 1150 para 1400 cigarros por ano e continua a crescer $1,7 \%$ por ano.

\footnotetext{
* Enfermeira e advogada. Professora Titular do Departamento de Orientação Profissional, Escola de Enfermagem da Universidade de São Paulo.

** Estudante do $4^{\circ}$ ano de graduação da Escola de Enfermagem da Universidade de São Paulo, contemplada com a bolsa PIBIC do CNPq, 1998-99
} 
Em novembro de 1982 a OMS(21) realizou uma reunião de especialistas sobre estratégias para controle de tabagismo nos países em desenvolvimento. O objetivo da reunião não era apenas enfatizar os efeitos nocivos do hábito de fumar, relacionados com as condições existentes nesses países, mas também ressaltar a necessidade de um esforço concentrado, pois esses países costumam ser alvo de campanhas promocionais mais agressivas dos fabricantes multinacionais de cigarros.

Um outro grupo de especialistas já, em 1978, alertava que na ausência de uma ação determinada e enérgica do governo, haveria uma probabilidade muito grande de que, dentro de uma década, a epidemia do tabagismo viesse a afetar esses países fazendo que um problema evitável de saúde pública viesse a impor uma carga pesada sobre sua população, aumentando ainda mais a distancia entre países ricos e pobres.

A OMS(24) alertava no Dia Mundial Sem Tabaco, 31 de maio de 1996, que a cada 10 segundos mais uma pessoa morreria como resultado do uso do tabaco e estimava que seus produtos teriam causado cerca de 3 milhões de mortes a cada ano no inicio da década de 90 e que esta cifra estava aumentando de forma muito estável. A menos que essa tendência fosse revertida, esses dados aumentariam para 10 milhões por ano até o ano 2020 ou começo da década de 2030, sendo que $70 \%$ dessas mortes ocorreriam nos países em desenvolvimento. Supõe-se que, até o final do século, o cigarro será a forma mais predominante do uso de tabaco.

Desde o início da década de 70, quando se percebeu essa tendência alarmante, a comunidade global da saúde, através da Assembléia Mundial da Saúde, aprovou 14 resoluções recomendando que os seus países membros adotassem amplas medidas para controle do fumo. Para obter dados confiáveis a OMS(21) elaborou padrões metodológicos para levantamento desde 1983. Assim, tem crescido o número de países que fazem levantamentos sobre prevalência de tabagismo utilizando essa metodologia e, portanto, com resultados confiáveis e comparáveis.

Guias da OMS(23) definem e classificam os fumantes em fumantes diários, ocasionais e atuais. A maioria dos países membros, que realizam levantamentos sobre prevalência do tabagismo, informa dados sobre o número de fumantes diários, considerado o indicador básico da prevalência que tem sido utilizado pela OMS. As limitações encontradas referiam-se a algumas diferenças de definição, métodos usados no levantamento e outros bias que reduzem a comparabilidade dos dados. Apesar dessas limitações, a OMS conseguiu dados razoavelmente confiáveis de 87 países do total de 190 países membros ou seja $85 \%$ da população mundial.

A Organização Panamericana de Saúde(OPS) ${ }^{(13)}$ faz uma estimativa global (dados de 1990) de que há cerca de 1,1 bilhão de fumantes em todo o mundo dentro de uma população de 15 ou mais anos de idade. A vasta maioria (cerca de 800 milhões) encontra-se nos países em desenvolvimento, e desse total 700 milhões são do sexo masculino. De uma forma global, estima-se que $47 \%$ de homens e $12 \%$ das mulheres fumam. Na região das Américas, essa mesma relação era de 35 homens para 22 mulheres e no Brasil, com dados de 1989, a relação era de 39,9 para 25,4 , isto é, há mais homens e mulheres fumando do que a média no continente.

Reunindo elementos tais como: a suposição de que profissionais da área de saúde conhecem melhor os males e conseqüências do fumo para a saúde e, por isso, teriam valor instrumental em campanhas para controle desse hábito; a observação sobre o aumento da prevalência de tabagismo entre as mulheres e que estas constituem a grande maioria $(90 \%)$ da população de enfermeiros e pessoal de enfermagem em praticamente todos os países do mundo, inclusive no Brasil; e, esse dado curioso sobre a prevalência desse hábito entre as mulheres brasileiras despertou interesse para saber quantos dentro da população (maioria de jovens do sexo feminino) dos que se preparavam para entrar na profissão de enfermagem já traziam o hábito de fumar ou, se esse hábito era adquirido no periodo preparatório, ainda durante os estudos de graduação.

\section{São portanto objetivos deste estudo:}

- levantar dados sobre a população de estudantes do curso de graduação da Escola de Enfermagem que fumam diária ou ocasionalmente;

- verificar se esse hábito já existia antes do ingresso do estudante na Escola ou se foi adquirido na própria Escola ;

- identificar quem pode ter influenciado na aquisição desse hábito;

- identificar os motivos que levam o estudante de enfermagem a fumar.

Com esses elementos pretende-se propor estratégias que possam contribuir para reduzir o tabagismo entre estudantes de graduação de enfermagem, que serão os futuros enfermeiros.

\section{REVISÃO DA LITERATURA}

Embora o cigarro manufaturado seja considerado pela $\mathrm{OMS}^{(23)}$ a forma predominante para o consumo de tabaco em todo o mundo, existem outros métodos de consumo. O fumo em rolos ou secos e soltos a granel em que o fumante prepara, em palhas de milho ou papel, o seu próprio cigarro, o charuto (com tabaco curado ou fermentado e enrolado em folhas do próprio tabaco) e o fumo consumido em cachimbos de madeira ou cerâmica são as formas mais comuns no Brasil. 
Um estudo transversal foi realizado na cidade de Pelotas, por HORTA et a1(5), sobre a prevalência do hábito de fumar, por meio de visitas e entrevistas de casas sorteadas. Estudou-se uma amostra probabilística de 1.401 adultos, com $11 \%$ de nãoresposta. Dos entrevistados, $54 \%$ nunca haviam fumado, $14 \%$ eram ex-fumantes e $33 \%$ fumantes, sendo que $16 \%$ fumavam 20 ou mais cigarros por dia. O tabagismo era mais freqüente entre os homens $(44 \%)$ do que entre as mulheres $(23 \%)$.

MORAES et $\mathrm{al}^{(10)}$ também fizeram um estudo na cidade de Amparo, no Estado de São Paulo, sobre a prevalência do tabagismo em escolares do $1^{\circ}$ e $2^{\circ}$ graus, considerado um dos grupos prioritários, pois é nessa faixa etária que esse hábito pode ser iniciado e também pode ser mais facilmente abandonado. Os autores concluíram que, embora a prevalência geral pudesse parecer baixa (6\%), o grupo de alunos, de 14 a 18 anos e mais, apresentava uma prevalência de $51 \%$.

Outro estudo transversal sobre determinantes do hábito de fumar entre estudantes de Medicina da Universidade Federal de Pelotas foi feito por HORTA et $\mathrm{al}(6)$. Dos entrevistados, $21,6 \%$ eram fumantes regulares e $7,3 \%$ ex-fumantes, mas não havia associação entre o tabagismo dos pais e o hábito de fumar dos filhos. Numa investigação específica sobre a associação do hábito de fumar entre os estudantes de Medicina de Brasília e seus pais, feita anteriormente por PAINE et al(14), também não foi encontrada essa relação.

$\mathrm{Na}$ área de enfermagem, um estudo sobre o hábito de fumar entre docentes e discentes foi feito por VALENTE et al(20) em três escolas de enfermagem no município de São Paulo. Numa população de 636 estudantes foi encontrado $24,1 \%$ de fumantes, $68,5 \%$ de não fumantes e $7,4 \%$ de ex-fumantes e entre 117 docentes, $23,1 \%, 62,4 \%$ e $14,5 \%$ respectivamente. Foi verificado que a causa mais freqüente que levou ao hábito de fumar, tanto no grupo de discentes como de docentes, foi a curiosidade, $(35,2 \%$ e $28,2 \%$, respectivamente) e ao abandono foi a consciência sobre os maleficios do fumo para a saúde $(72,5 \%$ e $65,2 \%$, respectivamente). Também foi encontrado que esse era o motivo dos não fumantes nunca terem iniciado o hábito de fumar.

Por todos esse maleficios à saúde que o hábito de fumar pode causar aos seus usuários a indústria do fumo vem sendo acionada a pagar altas indenizações às vitimas do fumo ou seus familiares. Nos Estados Unidos, segundo TOMKINS (18), esse cerco aos fabricantes de cigarros é patrocinado pela maioria dos Estados americanos. No Estado da Flórida, os fabricantes concordaram em pagar 11 bilhões de dólares nos próximos 25 anos para custear os gastos feitos pelo Estado no tratamento de doenças relacionadas com o hábito de fumar. Uma corte da
Califórnia (8) condenou uma grande empresa fabricante de cigarros a pagar uma indenização de US\$51,5 milhões de dólares a uma ex-consumidora de seus produtos que enfrentava um câncer de pulmão.

LEUENBERGER et al(9) fizeram um estudo para examinar os efeitos da exposição passiva prolongada ao fumo sobre a saúde respiratória de adultos. A amostra aleatória era composta de 4.197 adultos que nunca haviam fumado, procedentes de oito regiões da Suíça. Descobriram que, de fato, há associação entre essa exposição passiva ao fumo e sintomas de bronquite crônica, asma e outras formas de dispnéia, não associado a gripes ou resfriados. Não foi constatada relação com rinite alérgica. Verificaram também que os riscos de bronquite crônica eram maiores quanto maior fosse o tempo da exposição ao fumo. Talvez estimulados por esse estudo, fumantes passivos estão acionando as indústrias do fumo e obtendo as primeiras vitórias, como os comissários de bordo de aviões que, sendo não-fumantes, eram obrigados a trabalhar nas seções de passageiros fumante(7). Família de fumante brasileiro também já obteve uma primeira decisão judicial inédita, em primeira instância, em que uma companhia de cigarros foi condenada a pagar indenização em dinheiro e uma pensão mensal por 35 anos, refere PAIXÃO(15). Um outro ponto a destacar é que a responsabilidade dessas indústrias não é apenas com seus usuários viciados, mas com os não-viciados, que são obrigados a arcar com o custo do vício, ou seja os custos de doenças decorrentes do fumo. Mesmo que fumar seja uma atividade legal e as indústrias produzam seus cigarros de forma regulamentada e paguem os devidos tributos, seria necessário cobrar delas também os custos que são hoje repassados para os contribuintes. Como refere NASSIF (12) em nenhum sistema legal são cobradas indenizações dos viciados. Quem promove o vício é que devia pagar.

\section{MATERIAL E MÉTODO}

População - inclui todos os estudantes do curso de graduação, regularmente matriculados no segundo semestre de 1998, na Escola de Enfermagem da Universidade de São Paulo(EEUSP) e que totalizaram 314 estudantes, sendo 94 do $1^{\circ}$ ano, 65 do $2^{\circ} ; 75$ do $3^{\circ} \mathrm{e}$ 80 do $4^{\circ}$ ano.

Instrumento - foi um questionário, com perguntas abertas e fechadas, preenchido por esses estudantes da EEUSP, no intervalo de aulas do período letivo de setembro a dezembro de 1998. Uma aluna, na ocasião, do $3^{\circ}$ ano do curso de graduação, bolsista do Programa Institucional de Bolsas de Iniciação Científica - PIBIC, do Conselho Nacional de Desenvolvimento Científico e Tecnológico - CNPq, colaborou diretamente na distribuição e coleta dos questionários aos estudantes em todas as séries. Os 
estudantes foram solicitados a preencher o questionário no intervalo da aula e devolvê-lo preenchido para a estudante bolsista do PIBIC. Alguns estudantes preferiram levar os questionários para casa e devolvê-los preenchidos, marcando local, data e hora da entrega. A bolsista estava munida de uma listagem nominal de todos os estudantes para registrar a quem foram entregues e quem os havia devolvido. Isso facilitava a cobrança da devolução, quando necessário. O projeto teve início em setembro de 1998 quando alunos do último ano estavam finalizando alguns estágios práticos e preparando a monografia de final do curso. Assim, não havia mais aulas magistrais em grupo na Escola, comparecendo individualmente para entrevista com os orientadores em dias e horários dispersos. Por isso, muitos alunos do $4^{\circ}$ ano foram abordados para preencher os questionários, em dezembro, nos dias 7, 8 e 9, quando a classe foi dividida em três grupos para apresentação de suas monografias em sessão poster, nas dependências da Escola.

Conforme explicado na carta inicial ao estudante, a bolsista treinada procurou assegurar a liberdade de responder ao questionário, não insistindo na devolução do questionário, em caso de resistência ou desinteresse. Os questionários foram separados apenas de acordo com o semestre em que os alunos estavam matriculados. Posteriormente eles foram codificados, dando-se-lhes um número seqüencial aleatório a todos os questionários respondidos, sucedidos pelas letras A,B,C ou D, conforme eram os questionários do $1^{\circ}, 2^{\circ}, 3^{\circ}$ ou $4^{\circ}$ ano do curso. Não havendo outro tipo de identificação do questionário, os dados nele contidos puderam ser tratados confidencialmente e o fato de haver ou não respondido ao questionário não implicou na avaliação do aluno.

$\mathrm{Na}$ conceituação de fumante, foi utilizada a definição da OMS contida nos seus guias ${ }^{(21)}$. Segundo essa definição, é considerado:
1. Fumante - aquele que fumava na data do estudo. Pode ser classificado em:

a) Fumante diário ou habitual - aquele que fuma diariamente, mesmo que eventualmente passe um dia sem fumar.

b) Fumante ocasional - aquele que fuma socialmente ou em determinadas situações. Os fumantes ocasionais podem ter sido fumantes diários mas, no momento fumam apenas ocasionalmente, ou pessoas que não fumaram o equivalente a 100 cigarros, mas continuam a fumar ocasionalmente.

2. Não fumante - aquele que não fumava na data do estudo. Pode ser classificado em:

a) Ex-fumante diário - aquele que fumou diariamente e deixou completamente de fumar.

b) Ex-fumante ocasional - aquele que fumava ocasionalmente e deixou de fazê-lo.

c) Não fumante, propriamente dito - nunca fumou de forma alguma e não fuma atualmente.

Neste estudo com uma população presumidamente jovem, consideramos ex-fumante diário ou habitual ou ex-fumante ocasional aquele que deixou de fumar há pelo menos cinco anos. O fumante passivo não está incluído neste estudo.

\section{RESULTADOS E DISCUSSÃO}

Do total de 314 estudantes matriculados no curso de graduação da EEUSP, 21 (6,7\%) eram do sexo masculino e 293 (93,3\%) do sexo feminino. Dessa população de matriculados, responderam ao questionário 254 (80,9\%), sendo 237 do sexo feminino e 17 do sexo masculino, e coincidentemente, tanto na população feminina como na masculina, os respondentes atingiram $80,9 \%$, segundo se verifica na Tabela 1.

Tabela 1 - População de alunos matriculados no curso de graduação da EEUSP,, distribuídos por série e sexo, e porcentagem dos que responderam ao questionário, 1998

\begin{tabular}{|c|c|c|c|c|c|c|c|c|c|}
\hline \multicolumn{2}{|c|}{ Série } & \multicolumn{3}{|c|}{ Feminino } & \multicolumn{3}{|c|}{ Masculino } & \multicolumn{2}{|c|}{ Tota } \\
\hline $\begin{array}{c}\text { Número } \\
\text { absoluto e em } \\
\text { porcentagem }\end{array}$ & $\begin{array}{c}\mathrm{n}^{\circ} \mathrm{de} \\
\text { matriculados }\end{array}$ & $\begin{array}{c}\mathrm{N}^{\circ} \mathrm{de} \\
\text { respondentes }\end{array}$ & $\%$ & $\begin{array}{c}\mathrm{N}^{\circ} \mathrm{de} \\
\text { matriculados }\end{array}$ & $\begin{array}{c}\mathrm{N}^{\circ} \text { de } \\
\text { respondentes }\end{array}$ & $\%$ & $\begin{array}{c}\mathrm{n}^{\circ} \mathrm{de} \\
\text { matriculados }\end{array}$ & $\begin{array}{c}\mathrm{N}^{\circ} \mathrm{de} \\
\text { respondentes }\end{array}$ & $\%$ \\
\hline $1^{\circ}$ ano & 90 & 62 & 68,9 & 4 & 2 & 50,0 & 94 & 64 & 68,1 \\
\hline $2^{\circ}$ anos & 60 & 51 & 85,0 & 5 & 5 & 100,0 & 65 & 56 & 86,2 \\
\hline $3^{\circ}$ anos & 69 & 61 & 88,4 & 6 & 4 & 66,7 & 75 & 65 & 86,7 \\
\hline $4^{\circ}$ anos & 74 & 63 & 85,1 & 6 & 6 & 100,0 & 80 & 69 & 86,3 \\
\hline Total & 293 & 237 & 80,9 & 21 & 17 & 80,9 & 314 & 254 & 80,9 \\
\hline
\end{tabular}


Do total de 254 respondentes, a maioria absoluta, ou seja 229 ou 90,15\% eram solteiros, 20 alunos ou $7,9 \%$ eram casados ou viviam maritalmente, dois $(0,8 \%)$ eram viúvos e apenas um era divorciado ou separado. A absoluta maioria dos estudantes era constituída por jovens de até 25 anos de idade, o que retrata uma característica da população-alvo deste estudo. De fato, a população com até essa idade foi de $87,0 \%$ e de $13,0 \%$ acima dessa idade. Acima de 30 anos foram encontrados 13 alunos $(5,1 \%)$ e nenhum dos respondentes tinha 40 anos ou mais.

Com relação à procedência, verificou-se que 238 ou 93,7\% procediam de São Paulo, sendo 173 ou 68,1\% apenas da capital do Estado. Cinco estudantes eram nascidos em outros países, porém radicados no Brasil, não sendo encontrado nenhum estudante bolsista procedente de outro país.

Jovens nessa faixa etária, em geral, não possuem filhos e a realidade encontrada demonstrou que, de fato, a maioria absoluta de 240 (94,5\%) sobre 254 respondentes não tinham filhos. Entretanto nove alunos (sendo 6 , do $4^{\circ}$ ano) possuíam um filho e três estudantes possuiam dois ou mais filhos. Dois estudantes não responderam a essa questão.

Com relação à escolaridade dos pais, 34 respondentes mencionaram que seus respectivos pais tinham o $1^{\circ}$ grau ou ensino fundamental incompleto e 32 possuíam a mãe nessa mesma situação. Estudos anteriores como o de $\mathrm{NAKAME}^{(11)}(1976)$ e de ARCURI et al(2) (1983) mostram que o nível educacional dos pais naquela época, décadas de 70 e inicio de 80 , era inferior aos dados encontrados neste estudo. NAKAMAE(!!), embora tenha encontrado pais analfabetos $(2,7 \%)$, a maioria $(47,0 \%)$ tinha primário completo ou incompleto e apenas $12,7 \%$ tinha formação superior completa. STUART(17) (1993) relata, em seu estudo feito no Canadá, que o nivel educacional dos pais influencia na formação dos filhos, e demonstrou que as expectativas educacionais da mulher dependem da classe social dos pais, e que a enfermagem havia se tornado a carreira aceitável para as filhas de pessoas de prole numerosa e que tinham recursos moderados. Assim, em termos de esolaridade dos pais de estudantes de enfermagem, parece ter ocorrido um salto de qualidade no final da década de 90, pelo menos na USP, pois, $81(31,8 \%)$ respondentes informaram ter pai com curso superior completo, sendo a maioria (28) constituida por pais de estudantes do $1^{\circ}$ ano. Nesta série, do total de 94 matriculados, 64 responderam, o que significa que $43,7 \%$ dos pais de alunos respondentes tinham formação superior, o que representa quase quatro vezes os dados de 1976. Também o maior número de mães (17) com curso superior completo foi encontrado entre estudantes dessa mesma série. Como ambos os grupos pertencem ao $1^{\circ}$ ano, de recém-ingressantes na EEUSP, estudo mais porme-norizado sobre o tema poderia revelar, talvez, que pais com maior nivel de educação 24 formal estejam apoiando seus filhos a buscarem na enfermagem o caminho da profissionalização, e com isso também que a enfermagem esteja sendo vista mais positivamente pela sociedade do que há alguns anos.

Do total de 254 respondentes, 236 ou 92,9\% possuem um ou mais irmãos e $18(7,1 \%)$ são filhos únicos. A maioria $(72,4 \%)$ tem um a dois irmãos ou irmãs, e 52 alunos $(20,5 \%)$ tem três irmãos ou irmãs ou mais.

Dessa população de irmãos ou irmãs dos respondentes, foi encontrado que 18 tinham um único irmão fumante e 22 possuíam uma única irmã fumante. Em números absolutos, dentro dessa população consangüinea dos respondentes, parece que são as mulheres que estão fumando mais, porém tal afirmação não poderia ser feita sem um estudo mais aprofundado. Apenas 6 respondentes tinham dois ou mais irmãos/irmãs fumantes.

Do total de respondentes, 125 alunos ou 49,2\% já experimentaram fumar e 128 ou 50,4\% nunca experimentaram, e apenas um aluno do $4^{\circ}$ ano deixou de responder a essa pergunta do questionário. Dentre os respondentes que já experimentaram fumar, 33 $(13 \%)$ fumam apenas socialmente, mas 18 alunos $(7,0 \%)$ não responderam a essa pergunta do questionário. Não houve resposta alguma positiva quanto ao hábito de fumar charuto ou cachimbo.

Segundo a Tabela 2 a maioria absoluta, ou seja, 211 alunos $(83,0 \%)$ não fumam atualmente, aí incluídos 32 ex-fumantes, e $38(15,0 \%)$ alunos fumam, sendo que desses, 16 (6,3\%) são alunos formandos do $4^{2}$ ano e $5(2,0 \%)$ alunos não responderam à pergunta. Podese considerar positivo esse resultado de mais de $80 \%$ de não-fumantes ou ex-fumantes, entre todos os respondentes.

Tabela 2- Distribuição de alunos da EEUSP, que fumam atualmente, 1998

\begin{tabular}{lcccc}
\hline Série & Sim & Não & Sem resposta & Total \\
\hline $1^{\circ}$ ano & 8 & 56 & & 64 \\
$2^{\circ}$ ano & 7 & 49 & & 56 \\
$3^{\circ}$ ano & 7 & 56 & 2 & 56 \\
$4^{\circ}$ ano & 16 & 50 & 3 & 69 \\
Total & 38 & 211 & 5 & 254 \\
\hline \hline
\end{tabular}

Do total de 38 fumantes, a maioria, 23 alunos $(60,5 \%)$, começou a fumar com idade entre 16 e 20 anos de idade e $12(31,6 \%)$ antes de completar 15 . Apenas 3 (7,9\%) começaram com 21 anos ou mais.

Outro pormenor importante a investigar era o número de cigarros fumados, em média, pelos estudantes que responderam ao questionário. A maioria dos estudantes fumantes, ou seja 22 (57,9\%)

Rev.Esc.Enf. USP, v. 35, n. 1, p. 19-27, mar. 2001. 
fumam de 6 a 20 cigarros por dia, e 15 alunos (39,5\%) fumam de 1 a 5 cigarros por dia e apenas um estudante $(2,6 \%)$ do $4^{\circ}$ ano mencionou fumar mais de um maço por dia.

Segundo informaram, a grande a maioria dos estudantes, ou seja, $37(97,4 \%)$ começaram a fumar por curiosidade própria, 16 alunos $(42,1 \%)$ foram influenciados por colegas/amigos de escola, e apenas 3 estudantes $(7,9 \%)$ foram influenciados por pais e familiares, o que mais uma vez comprova a ausência de associação entre pais tabagistas e seus filhos. Apenas 2 estudantes $(5,3 \%)$ sofreram influência de uma pessoa que admiravam. Nesta questão os alunos poderiam assinalar mais de uma opção.

De acordo com dados colhidos, a maioria absoluta dos 34 estudantes fumantes $(87,2 \%)$, fumam porque consideram esse habito relaxante, 11 alunos $(28,2 \%)$ para aliviar o cansaço, e outros $11(28,2 \%)$ porque o fumo dá sensação de prazer e liberdade, e por ser um hábito comum entre colegas. Dentre outros motivos alegados, $3(7,9 \%)$ fumantes mencionaram fumar por ser um vício, $2(5,2 \%)$ porque ajuda a não engordar e acham bonito o ato de fumar.

Dentre os 38 fumantes, 20 estudantes $(52,6 \%)$ manifestaram desejo de parar de fumar, $6(15,8 \%)$ não querem, e $11(28,9 \%)$ alegaram ainda não saber, se querem, ou não, parar de fumar e um $(2,6 \%)$ não respondeu à pergunta. Metade dos ex-fumantes $(50,0 \%)$ mantiveram esse hábito por um período de 1 a 6 meses, $6(18,7 \%)$ por 1 a 3 anos e $6(18,7 \%)$ fumaram por mais de 3 anos.

$\mathrm{Na}$ questão sobre os motivos que levaram os respondentes a cessar o hábito de fumar, o aluno poderia assinalar mais de um motivo. A iniciativa própria foi o motivo mais freqüentemente alegado por 27 estudantes ex-fumantes. Outros motivos mais freqüentes foram problemas de saúde e influência de colegas/amigos de escola. Apenas um aluno exfumante alegou ter sofrido pressão familiar para deixar de fumar, o que foi menor que a influência de uma leitura sobre o assunto, do exemplo ou recomendação de alguém que fosse objeto de admiração do aluno. Nenhum aluno alegou problema econômico como motivo para cessar de fumar.

Segundo os respondentes, a maioria dos exfumantes, isto é, $14(40,0 \%)$ estão em abstenção de fumo de 13 a 60 meses (5 anos), $11(31,4 \%)$ já estão em abstenção por mais de 5 anos e $10(28,6 \%)$ alunos estão em abstenção de fumo por menos de 1 ano. De fato, esses 10 alunos, sendo dois do $1^{\circ}$ ano, pararam de fumar depois de ingressarem no curso de enfermagem, o que permite pensar que um dos motivos tenha sido a aquisição de conhecimento sobre os males do fumo à saúde.

A última pergunta do questionário era aberta e os estudantes poderiam declarar livremente os motivos que os levaram a nunca ter fumado ou não pretender fumar. Dentre os três motivos mais citados pelos respondentes foram encontrados: ser o fumo prejudicial à saúde, ter mau cheiro e não gostar desse habito. Outros motivos alegados em menor proporção estão alergia ou ser causa de doenças pulmonares e cardiovasculares, ou porque não é costume familiar e também por estar cursando enfermagem e não querer prejudicar o ar ambiente. Outros estudantes consideraram vulgar o hábito de fumar, ou não fumam por questão de estética.

\section{CONCLUSÕES}

Os resultados obtidos dos dados levantados e analisados permitem concluir que:

1) Do total de 314 estudantes matriculados em todas as séries do curso de graduação da EEUSP, 254 $(80,9 \%)$ responderam ao questionário, instrumento deste estudo. Desse total de respon-dentes, 237 (93,3\%) eram estudantes do sexo feminino, o que não surpreende em um curso tradicionalmente considerado feminino.

2) A maioria dos respondentes $(93,7 \%)$ procedia de São Paulo e eram solteiros $(90,2 \%)$ e sem filhos (94,5\%).

3) Fato inusitado foi encontrar 132 ascendentes, sendo 81 pais e 51 mães, de respondentes totalizando $25,9 \%$ com formação superior completa. Incluindo-se 41 pais com formação superior incompleta, esse total seria de $34,05 \%$. A maioria desses ascendentes eram pais de alunos do $1^{\circ}$ ano de graduação, o que poderia significar que as novas gerações estão encontrando maior apoio dos pais na escolha da profissão de enfermagem, o que até recentemente não ocorria nessa proporção, especialmente entre estudantes procedentes de familias com maior preparo intelectual.

4) Do total de 254 respondentes, 236 (92,9\%) possuem um ou mais irmãos ou irmãs. Os demais $7,1 \%$ são filhos únicos. Dentro dessa população, 18 alunos tinham um irmão fumante e 22 uma irmã fumante. Apenas 6 respondentes afirmaram ter dois ou mais irmãos fumantes.

5) Da população que respondeu ao questionário, 125 $(49,2 \%)$, ou seja quase a metade dos alunos já havia experimentado fumar. Destes, 33 (13\%) alegavam fumar apenas socialmente e 18 deixaram essa questão sem resposta. Não foi encontrado entre os respondentes, nenhum aluno que fumasse charuto ou cachimbo.

6) Entre os respondentes, 211 estudantes afirmaram não estar fumando na data do estudo, contra 38 $(15,0 \%)$ que responderam positivamente. Cinco não responderam essa pergunta. Dentre os fumantes, 16 $(6,7 \%)$ eram alunos do $4^{\circ}$ ano, e os demais estavam dispersos nas outras séries do curso. 
7) Desse total de 38 fumantes encontrados entre os respondentes, a maioria, 23 (60,5\%) estudantes, começou a fumar entre os 16 e 20 anos de idade, 12 $(31,6 \%)$ com menos de 15 e $3(7,9 \%)$ com 21 anos ou mais. Pode-se inferir a partir desses dados, que provavelmente a maioria começou a fumar antes de ingressar na universidade. Três alunos mencionaram ter começado a fumar depois de entrar no curso de enfermagem, e que assim o faziam apenas socialmente, para acompanhar amigos e colegas fumantes.

8) 0 consumo de cigarros por dia pela maioria $(57,9 \%)$ de fumantes está em torno de 6 a 20. Quinze estudantes confessaram fumar de 1 a 5 cigarros e apenas um aluno do $4^{\circ}$ ano fuma mais de um maço por dia.

9) A maioria $(94,4 \%)$ começou a fumar por curiosidade e $47,4 \%$ foram influenciados por colegas ou amigos ou por pessoa que admiravam. Apenas 3 estudantes foram influenciados por pais ou familiares. Isto vem corroborar estudos anteriores que também não encontraram relação entre pais tabagistas e seus filhos.

10) A maioria absoluta das justificativas $(87,2 \%)$ encontradas entre os fumantes era de que fumavam porque consideravam esse hábito relaxante. Os alunos poderiam assinalar mais de um motivo que os levava a fumar. Assim, 22 alunos fumavam para aliviar o cansaço e pela sensação de prazer e liberdade. Outros alegaram fumar porque já era um vício ou por motivo estético, isto é, o fumo ajudava a manter o peso.

11) Dentre os 38 fumantes, $52,6 \%$ desejavam parar, mas 15,8\% não tinham esse desejo, enquanto 28,9\% não tinham certeza se queriam ou não. Apenas um fumante não respondeu essa pergunta.

12) Sobre a questão dos motivos que os levou a parar de fumar, 84,4\% das respostas foram atribuídas à iniciativa própria, 40,6\% por influência de colegas ou amigos, além de problemas de saúde. Apenas um aluno alegou ter cessado de fumar por pressão familiar. Interessante notar que nenhum aluno alegou problema econômico para deixar esse hábito.

13) Sobre o período de abstenção do fumo, a maioria, isto é, $40 \%$ abstiveram-se de fumar por um período variável entre um e cinco anos, $31,40 \%$ por mais de cinco anos.

14) Entre os motivos mais citados pelos alunos por nunca ter fumado foi que o fumo é prejudicial à saúde, tem mau cheiro e não gostam desse hábito. Outros motivos alegados foram: alergia, o fumo ser causa de doenças pulmonares e cardiovasculares, ou simplesmente por estar cursando enfermagem, não querer prejudicar o ambiente e não ser costume entre seus familiares. Houve estudantes que consideraram o fumo como um hábito vulgar ou anti-estético.

Em suma, a prevalência geral do tabagismo no grupo estudado pode ser considerado alto (15\%), levando-se em conta que se tratam de estudantes de enfermagem, e portanto, futuros profissionais da saúde, que não apenas tomam conhecimento teórico dos males do fumo, como têm oportunidade de contatar e cuidar de pacientes portadores de doenças causadas pelo tabagismo, apresentando todos os sintomas e conseqüências desse hábito. Como enfermeiros deveriam ser modelos de saúde e praticar na vida diária os melhores hábitos de saúde.

\section{RECOMENDAÇÕES}

$\mathrm{Na}$ qualidade de estudante e formanda de enfermagem, a co-autora deste estudo, pôde comprovar pelas observações pessoais feitas no decorrer dos quatro anos do curso, que há professores que fumam durante as aulas, embora deva ser salientado que não eram enfermeiros-docentes. Mesmo assim, essa coautora sentiu que não houve ênfase sobre os males do fumo nas disciplinas de enfermagem, e nem discussões sobre esse hábito, seja durante as aulas teóricas seja no campo de estágio prático.

Assim à guisa de recomendações práticas, sugere-se que a EEUSP adote o seguinte:

- Colocação de maior quantidade de placas de "proibido fumar" nos corredores, salas de aula e outras dependências da Escola e, para os que optassem por continuar com esse hábito, poderia ser destinado uma sala ou local com ventilação apropriada para esse fim.

- Realização de seminários periódicos sobre tabagismo com incentivo aos alunos e enfermeirosdocentes para que deixem de fumar. Poder-se-ia mesmo estimulá-los a utilizar os modernos métodos de autoajuda e até uma aplicação da teoria do auto-cuidado para esse fim.

- Participação ativa da EEUSP no dia 31 de maio, Dia Mundial sem Tabaco, com temas específicos para cada ano, promovido anualmente pela OMS, e que conta com o apoio oficial do Ministério da Saúde, com organização de exposições, palestras ou filmes sobre o assunto. Em 1999, o tema lembrava os fumantes para que jogassem fora o maço ${ }^{(25)}$.

- Inclusão dessa atividade no programa da Comissão de Cultura e Extensão Universitária (CCEx) da EEUSP, o que constituiria em mais uma contribuição da Escola para a comunidade leiga ou profissional, com a difusão de conhecimentos sobre promoção da saúde.

- Maior ênfase nas aulas durante todo o curso de enfermagem sobre os males causados pelo tabagismo e estimular enfermeiros-docentes para serem, de fato, modelos de saúde para os alunos, para que estes possam refletir tal comportamento no futuro, como profissionais da saúde. 
Epidemiologicamente, as maléficas conseqüências do tabagismo têm sido estudadas e análises estatísticas comprovam uma relação significativa entre o hábito de fumar, a incidência de doenças cardíacas e mortalidade (24). A mortalidade e a incidência de doenças coronárias são mais altas entre fumantes, inclusive mulheres que usam contraceptivos orais. O hábito de fumar como fator causal no desenvolvimento de câncer dos pulmões e outros órgãos tem sido confirmado tanto em homens como em mulheres.

O número de mulheres fumantes tem aumentado progressivamente, não apenas porque a população mundial tenha crescido, mas também porque o hábito de fumar é encorajado pelas campanhas comerciais, apesar das evidências irrefutáveis de mortalidade e doenças relacionadas como conseqüência desse consumo, somados à pouca ação dos governos. Até recentemente a incidência e as taxas de mortalidade de doenças relacionadas com o tabagismo eram muito menores entre as mulheres do que entre os homens ${ }^{(22)}$. Hoje é sabido que as mulheres são suscetiveis às mesmas doenças dos homens relacionadas com o tabaco, além de serem afetadas por outras condições especificas.

Os componentes mais maléficos do tabaco são o alcatrão, o monóxido de carbono e a nicotina. O papel carcinogênico do alcatrão já foi bem estabelecido em muitos trabalhos científicos documentados pelo Centro de Controle de Doenças ${ }^{(19)}$ em 1991. A nicotina e o monóxido de carbono contribuem particularmente para o aumento do risco de desordens cardiovasculares interferindo na oxigenação do sangue nos pulmões, assim como no volume de vasos coronarianos. A cessação do hábito de fumar, mesmo que por períodos curtos tem mostrado ser benéfica para a saúde.

A relação entre tabagismo como causa de bronquites crônicas tem também sido amplamente demonstrada. A prevalência de tosse e expectoração é significativamente mais alta entre fumantes do que entre ex-fumantes ou não fumantes.

Um considerável risco de doenças respiratórias ou de pulmão, como a bronquite crônica, entre crianças obrigadas a respirar ar poluído com fumaça de cigarro tem sido relatado, sendo que o grau de risco depende também do número de fumantes na família. Ser fumante passivo, isto é, conviver com fumantes, é visto como um possivel risco para o desenvolvimento de câncer do pulmão em não-fumantes.

A maioria desses dados foram estudados ou obtidos em países desenvolvidos, mas o conjunto de evidências prova que os efeitos negativos do fumo sobre a saúde são individualmente os mesmos em países desenvolvidos ou em desenvolvimento. Entretanto, os efeitos nocivos sobre a saúde podem ser maiores na população dos países em desenvolvimento em conseqüência das condições nutricionais e a presença de enfermidades infecciosas, mais comuns nesses países.

O Conselho Internacional de Enfermeiras (CIE), desde 1989, tem assumido uma posição firme em relação ao tabaco e saúde, afirmando que a responsabilidade fundamental do enfermeiro é a de promover a saúde e prevenir a enfermidade e considera o hábito de fumar um dos problemas mundiais de saúde mais fáceis de evitar. Reconhecendo que o hábito tem crescido especialmente entre mulheres e jovens, o CIE") compromete-se a trabalhar com as associações nacionais de enfermagem e incentivar métodos para que enfermeiros fumem menos ou deixem completamente de fazê-lo, e desestimular que estudantes de enfermagem iniciem esse hábito. De acordo com essa politica de trabalho, nas reuniões do CIE é proibido o uso do tabaco.

ALDERMAN ${ }^{(1)}$ coordenou um levantamento sobre estilo de vida por meio de um questionário inserido ao acaso para 20.000 leitores do periódico "Nursing Standard". Analisando as respostas obtidas (1839) constatou que a maioria $(91,6 \%)$ era de respondentes do sexo feminino e que embora $85,2 \%$ declarassem consumir bebida alcoólica, apenas 14,3\% eram fumantes.

Alem do tabaco, outras características de fumantes poderiam aumentar seu risco de sofrer enfermidades relacionadas com o hábito de fumar, como por exemplo, a dieta alimentar. Provavelmente a prevalência mais elevada de câncer nessas pessoas esteja associada com sua menor ingestão de nutrientes com propriedades oxidantes e protetoras contra o câncer, como por exemplo, vitaminas C e E. Também a menor ingestão de ácidos graxos polissaturados poderia explicar a prevalência mais elevada de enfermidades cardiovasculares neste grupo. Num estudo transversal realizado na Inglaterra, por $\mathrm{CADE}^{(3)}$, sobre a relação entre tabagismo e dieta, analisaram-se as dietas de 1.115 homens e 1.225 mulheres entre 35 e 54 anos de idade para comparar a ingestão de nutrientes segundo três categorias do hábito de fumar: fumantes, ex-fumantes e não fumantes. Os resultados indicaram que a ingestão de vitaminas $\mathrm{C}$ e $\mathrm{E}$ e fibra total assim como a razão entre ingestão de gorduras polissaturadas e saturadas eram menores entre os fumantes que os não fumantes.

STEVENS (16) estudou a prevalência do hábito de fumar entre mulheres de idade fértil de Porto Rico e verificou que a prevalência de tabagismo era diferente entre distintos grupos de idade e que era maior entre mulheres de 20 a 24 anos. Ao analisar a prevalência segundo decênios de nascimento foi comprovado que nas cohortes de maior idade a proporção aumentava ao passar para a cohorte mais jovem. A prevalência variava também segundo a educação, estado civil e consumo de álcool. 
- Maior divulgação de dados e estatísticas da OMS, através de cartazes, boletins e informativos nos quadros de avisos na portaria e corredores da Escola, sobre pessoas que morreram em conseqüência direta do tabagismo, o custo social do tabagismo para a sociedade, os gastos da indústria de cigarros para a publicidade a fim de atraírem adolescentes e jovens com imagens de aventura, independência, elegância e charme para induzirem o hábito de fumar.

\section{REFERÊNCIAS BIBLIOGRÁFICAS}

1. ALDERMAN, C. Here's looking at you. Nurs Stand, v.11, n.16, p.32-27, 1997.

2. ARCURI, EM et al. Fatores que influenciaram alunos ingressantes na Escola de Enfermagem da USP, em 1981, na escolha da enfermagem como opção profissional. Rev Esc Enf USP, v.17, n.1, p.5-19, 1983.

3. CADE, $J$ et al. Relationship between diet and smoking . Is the diet of smokers different? J Epidemiol Community Health, v.43, p.270-2, 1991

4. CONSEJO INTERNACIONAL DE ENFERMERAS (CIE) Posiciones del CIE, Tabaco y salud. Aprobado en 1989 y revisado en 1993. Ginebra, 1993.

5. HORTA, BL et al. O hábito de fumar entre estudantes de Medicina da UFPEL: prevalência, sintomatologia respiratória e relação com o tabagismo dos pais. Rev AMRIGS, v.32, n.1, p.15-7, 1988

6. HORTA, BL et al. Determinantes do habito de fumar na cidade de Pelotas, Brasil. Bol Of Sanit Panam, v.113, n.2, p.131-6, 1992.

7. JONES, D. Passive smoking and protection of non smokers in Switzerland - possibilites for action! [on line] disponivel na internet via: www.no-smoke:org/ets.html,15 de out. de 1998.

8. JUSTIÇA condena empresa de cigarros a pagar US\$51,5 mi. Folha de São Paulo. São Paulo, 12 fev.1999. Cad.1, p.10.

9. LEUENBERGER, $J$ et al. Passive smoking exposure in adults and chronic respiratory symptoms (SAPALDIA STUDY) Am J Respir Crit Care Med, v.150, p.1221-8, 1994.

10. MORAES, MA et al. Estudo da prevalência do tabagismo em escolares do 10 e 20 graus - a criança e o adolescente como agente de mudança desse habito, no municipio de Amparo-SE Rev Bras Enf, v.44, n.1, p.60-9, 1991.

11. NAKAMAE, DD. Perfil do estudante de enfermagem. São Paulo, 1976. 68p. Dissertação (mestrado) Escola de Enfermagem, Universidade de São Paulo.

12. NASSIF, L. O custo do fumo e do álcool. Folha de São Paulo. S. Paulo, 31-12-98. Cad.2, p.3.

13. ORGANIZACION PANAMERICANA DE SALUD. Tabaco o salud: situación en las Américas, 1992. Washington, 1992. (Publicación Cientifica 536).
14. PAINE, PA et al. Association between Parental and Student Smoking Behaviour in a Brazilian Medical School. Int J Epidemiol, v.14, n.2, p.330-2, 1985.

15. PAIXÃO, R. Decisão inédita. Veja, São Paulo, p.87 ed., de $1^{\circ}$ de outubro de 1997.

16. STEVEnS, JA et al. Prevalência del habito de fumar en mujeres de edad fertil de Puerto Rico. Bol Of Sanit Panam, v.112, n.6, p.494-9, 1992.

17. STUART, ME. Nursing: the endangered profession. Can Nurse, v.89, p.19-22, 1993.

18. TOMKINS, R. Tobacco groups agree to pay health damages. Financial Times, London, , p.3, 1997.

19. US DEPARTMENT OF HEALTH AND HUMAN SERVICES, Public Health Services, Centers for Disease Control - Environmental tobacco smoke in the workplace: Lung cancer and other health effects. Current Intelligence Bulletin, 54, June 1991.

20. VALENTE, MA et al. O fumo entre docentes e discentes das escolas de enfermagem. Rev Esc Enf USP, v.16, n.2, p.14763, 1982.

21. WORLD HEALTH ORGANIZATION. Smoking Control Strategies in Developing Countries. Report of a WHO Expert Committee. Geneva, 1983. (Technical Report Series 695).

\section{WORLD HEALTH ORGANIZATION. Women and} Tobacco. Geneva, 1992

23. WORLD HEALTH ORGANIZATION. Guidelines for controlling and monitoring the Tobacco Epidemic. Tobacco or Health Programme. Geneva, 1996.

24. WORLD health ORGanization. Tobacco Alert. World No Tobacco Day 1996, Special Issue prepared by Collishaw, N.E. and Lopez, A.D. WHO Programme on Substance Abuse.

25. WORLD HEALTH ORGANizATION. World NoTobacco Day, 31 May 1999 - Leave the pack behind. Prepared by Neil Collishaw, Kate Koplan and Martin Jarvis. Geneva, 1999. 